April - 2002

\title{
Towards a Strategy for Improved Student Retention in Programmes of Open, Distance Education: A Case Study from the Open University UK
}

\author{
Susan Tresman \\ Director, Open University UK Student Retention Programme
}

\section{Teaching at a Distance}

Teaching at a distance has enjoyed a long history and is now established as a reputable method of education as evidenced by the establishment of numerous distance learning systems worldwide. One such system is the Open University UK, Britain's largest teaching institution, with 125,000 undergraduate students enrolled in the year 2000. Since first opening its doors in 1971, more than two million students have participated in studies at the Open University UK.

The Open University UK has a unique mission statement - open as to people, open as to places, open as to methods, and open to ideas - an "open access" policy that attracts students from a variety of backgrounds, all seeking a divergent range of study goals. With this mission mind, it is vital that the Open University UK secure the best possible chances for its students' success.

\section{Why is Student Retention Important?}

Student retention is clearly an issue of concern, the implication being that if the Open University has failed its students, the students have failed themselves. Government and financers of higher education are concerned about their investment in higher education, which they arguably perceive as squandered through student dropout. There are also issues surrounding reputation management, with dropout cited as a key indicator of poor or substandard performance. In this context, rightly or wrongly, distance education is often perceived as a model of education that has high dropout rates. With public funding of higher education in the UK linked to various performance outcomes, funding for higher education is now based on the number of students who successfully complete courses. In other words, funding may be cut if students fail to persevere and complete their coursework.

\section{Student Retention}

\section{The Theoretical Framework}

The issue of student retention is firmly located within a specific discourse and a specific theoretical framework, both of which are open to challenge. In recent years, UK higher education institutions have been thrust into the market economy by government, and now find themselves 
Tresman, Towards a Strategy for Improved Student Retention in Programmes

competing against each other for students and resources (Ball et al., 1997). Increasingly, students are being perceived as consumers, especially since the demise of the UK maintenance grants system. In simple terms, students must now finance their own higher education, primarily though the payment of tuition. Changes to the manner in which higher education is provided within the modern public sector, are clearly reflective of the government's growing concern surrounding the cost, quality and utility of higher education. To this end, the British government has adopted a series of principles for organising this particular social provision within its public sector. These principles include the need for increased access, greater integration of private/commercial interests, and allocation of public funds to fund such expansion. All this activity is hoped to pave the way to higher standards and greater accountability. Management principles have been applied to the field of education in an attempt to secure higher standards and greater efficiency of operation using discourses of excellence, quality and effectiveness (Ball, 1997). However, Ball is critical of the adoption of this "market economy" approach for three reasons. Firstly, there is a lack of engagement with sociological or other theory. Secondly, no account is taken of the political, social and economic context in which education is provided. Thirdly, it assumes that educational problems can be solved by technical means (Ball, 1995, 260-262). Instead, Ball argues for the need to look at situations and related processes as they actually exist, without clouding them with preconceived ideas. Only then can one reveal the truth of what is actually going on within existing practices, and to use data gathered to construct a theory that can duly guide policy and strategic planning. Careful observation and analysis of what is actually happening within a given institution, can lead to a theory that is both relevant to a given institution context, rather than that of the government.

Other, more traditional or philosophical approaches - many of which have been sidelined by current discourses - ask some fundamental questions. Questions such as: What is education? Education is for what and for whom? And what should education seek to achieve in relation to both society and the individual? As Carr (1997) puts it, the question we should be asking is: "What is . . . the role of education in the reproduction and transformation of the good society?" An obvious difficulty with the market economy approach to education is its assumption that students - i.e., consumers - are the best judges of their educational needs and how these should be met. This practice is, at best, open to question.

\section{Quality Improvement Models}

Quality improvement (QI) models are about institutional change and are based on industrial or commercial models of quality management, whose fundamental purpose is to improve quality, increase productivity and reduce costs mainly through the elimination of variance (Chaffee \& Sherr, 1992; Capper \& Jamison, 1993). Within these models, the educational process is seen as a consumer-led methodical process whose primary aim is to understand students as consumers. Put simply, student needs and expectations, as interpreted by government, must be addressed because they are consumers (Schwartz \& Peterson, 1993).

Within this new and currently popular QI framework, each non-completion of a given course is seen as the failure of an institution to fully meet the needs of its "customer," and therefore it must suffer financial repercussions following such a failure. As such, considerable energy has been recently expended in an attempt to determine exactly why students (consumers) choose to dropout. 


\section{Tinto’s Model}

Related to the progress of conventional campus students, the most popular theoretical model that seeks to understand the process of student withdrawal is that of Tinto (1975). Applying Tinto's model to adult learners studying at a distance, Kember postulated in 1995 that students' background characteristics interact and influence their initial commitment to their educational goals and their initial commitment to their chosen higher education institution. These commitments and characteristics influence students' intellectual development and academic performance, which, in turn, subsequently determine their degree of academic integration. This model asserts that students' perceptions of their social and academic integration are predominant influences in their decision to persist (or not to persist) in their studies. In sum, Kember attempts to explain the processes that bring individuals to leave higher education. For institutions using Tinto's model, student needs are a priority. By stressing the overall student experience, Tinto maintains that retention:

" . . . is not the goal of an institution; the goal is the social and intellectual development of students. Retention is the outcome of providing an experience so educationally beneficial and developmentally advantageous, that students will form favourable perceptions regarding the quality of their experience and decide to persist” (Peterson et al., 1997, p.138).

Tinto's model has been generally validated by considerable empirical evidence (Peterson et al., 1997, p. 134). However, some additional findings have also been gained thanks to the growing diversity of the UK's student bodies. Research focusing on older, part-time and non-residential students suggests other variables, beyond those set out by Tinto, are involved in students' decisions to withdraw or persist in their studies. These variables include students' initial educational objectives and intentions and their extra-institutional integration - i.e., the support they receive from family, peers and employers (Schwartz, 1990). Students, whose academic life is well integrated with their extra-institutional life, will be less inclined to withdraw from their studies than those for whom such integration is less well developed.

From Tinto's findings a key question has been raised: Are retention levels an indicator of students' perceptions of the quality of their educational experiences? (Peterson et al., 1997, p. 138). If so, will QI initiatives that aim to improve the quality of students' educational experiences, help facilitate student retention?

Recent research carried under the auspices of the Student Retention Project (Tresman, 2001) has revealed that a number of critical factors appear to affect persistence of part-time, mature students attending the Open University UK. These factors have been used to construct the Student Value Chain (SVC) that comprises both value enhancers and inhibitors derived from research. Students' reasons for dropping out have revealed a clear multi-dimensionality, supporting earlier findings made by Schwartz (1990). It is apparent that, in some cases, dropout occurs in relation to individual students' exceeding their personal thresholds, which they have failed to adequately establish through integration of their studies with their lifestyle. When dropping courses, they often cite: "The workload is too great." "The courses were too difficult." "The fees were too expensive."

If retention is in part a reflection of students' perceptions of quality and flexibility at the interface of the institution, as well as that of their overall experiences, then by inputting new sources of value/quality into the SVC, we may be able to design and implement measures to enhance student retention. This has been the approach used to develop the "Strategy for Enhanced Student 
Tresman, Towards a Strategy for Improved Student Retention in Programmes

Retention at the Institutional Level,” presented to Open University UK's senate in May 2001. Recommendations contained within this strategy were arranged to reflect the "student-learning journey.”

\section{Student Retention: Terminology, Definitions, and Interpretations}

In terms of both its definition and connotation, student retention is problematic. Student retention is about students who do not complete courses or programmes of study, although this term can also mean enrolling but not starting the course, formally withdrawing after starting studies, ceasing to participate in studies, participating but failing to reach the required standard, or moving on to another course or institution.

In that there is an implied assumption that all "non-completion" is undesirable, the phrase "student retention" is not value free. Non-completion is widely publicised in this vein through Britain's media. For instance, The Guardian newspaper (December 3, 1999) ran an article under the headline "University Drop-Out Reflects Class Roots," and went on to quote Britain's higher education minister, and the chief executive of the committee of vice-chancellors and principals, both whom spoke of "high dropout rates" and its being equated with failure. The words they used in relation to student retention include "wastage" and "attrition," both of which carry negative connotations. But it can also be argued that within a context of flexible and transferable course offerings designed to widen access, participation, and movement across and between institutions, some level of non-completion is, in fact, can be viewed as positive. Moreover, in terms of personal development, some students' learning objectives may be, in fact, met without formally completing a course. For example, students who drop their studies may find employment or simply regard non-completion as a brief interruption in their educational journey that is more reflective of personal circumstances than that of their long term educational goal. Nonetheless, interim results of recent research commissioned at the Open University, suggest that the vast majority who withdraw (94 per cent) still aspire to earn credit for the course/award upon which they embarked. Relevant research into these issues at the Open University UK is currently encompassed within the Student Retention Programme, which has been running since 1999 with a wide-ranging remit to examine aspects of academic and administrative significance so as far as student retention is concerned.

\section{The Student Learning Journey}

Students' learning journey starts with initial enquiry to the university and their first tentative steps into distance education that is usually underpinned with a plethora of questions linked to concepts like life long learning, re-establishing one's identity as a learner, assessing whether or not the distance education mode is suitable for them, and if the university matches their educational needs. More crucially, prospective students need to make informed choices. Obtaining a match between a prospective student's actual needs and a given course of study is of vital importance. To help make this match, the provision of clear and informative information delivered in a variety of formats such as electronic, paper, and face-to-face, helps to enable prospective students to make informed choices.

In such as system, however, the burden of choice still remains with prospective students. Although they are often provided with ample advice on issues such as course descriptions, course contents, qualifications, learning skills, time management techniques, student testimonials and the like, the choices they face often remain daunting. There are no restrictions on choices in terms of level or content, irrespective of the prospective students' past educational or life experiences. 
With a half-million enquiries made by potential students in a given year, the conversion rate between enquiry and the firm commitment to enrol at the Open University, currently stands at approximately 11 per cent. Key reasons cited by prospective students for not moving forward on their learning journey at the inquiry stage include: cost considerations, uncertainty about having sufficient time to commit to a programme of study, changes in personal circumstances, and often more tellingly, difficulty making a decision among a seemingly unlimited array of choices.

During the stage between course enrolment and the start of the course (which may range between a couple of weeks to a number of months) communication between the university and new enrolees heralds the start of a fledgling relationship in the educational contract. Five per cent of all students enrolled at the Open University are known to withdraw during this stage, a figure that rises to 15 per cent of first-time enrolees.

On average 15 per cent of new and 10 per cent of experienced students withdraw within the first three months of starting a course. After three months, withdrawal rates level out, with dropouts occurring across the academic year up to exam time. Typically, an additional 25 per cent of new students and 22 per cent of experienced students chose to dropout during the duration of the course.

All higher education institutions regard student dropout as an issue. Among UK's 163 higher education institutions featured in Higher Education Funding Council data for 1999, the average projected percentage of students who started fulltime (first degree) study in 1996, and who did not obtain a degree nor transfer to another institution, stands at 16 per cent. In this context, individual figures for specific higher education institutions ranging from one per cent (Cambridge University) to 36 per cent (University of East London). However, there appears to be no valueadded factoring to make individual comparisons fair in terms of (other) factors unique and specific to each institution.

From an international perspective, OECD data from 1998 show that among the 29 OECD states, including the United States, Germany and Australia, the UK's dropout rate was among the lowest at 19 per cent. This statistic can be compared to 37 per cent in the United States, 28 per cent in Germany, and 35 per cent in Australia. Additional research data suggest that withdrawal rates are generally higher for mature students involved in distance learning studying part time (McGivney, 1996), all of which are characteristics of the Open University UK’s student body.

If it is to be assumed that for the majority of the students who enrolled and fully intended to complete their course(s), but failed for whatever reason to do so, then this experience of nonachievement can not only be financially costly, but a significant blow to students' self-esteem and motivation as well. When viewed from this "self-esteem/motivational" perspective, student retention is clearly an issue for the Open University UK, an issue that is central to its goals irrespective of increasing external pressures by the government to use retention rates as a key indicator of performance.

\section{What Affects Student Progress on Their Learning Journey?}

Key issues that affect student progress include specific courses in which students are enrolled and the geographic regions in which students choose to study. For example, London and other large urban centres throughout the UK tend to have more transient populations, a factor that often translates into to higher student dropout rates. Also relevant is whether or not students are new to the Open University. Higher rates of dropout are recorded for novice students and students 
comprising at-risk demographic characteristics (e.g., gender, age, ethnic background and previous educational qualifications, etc.). Tutorial quality is also a significant issue. In the year 2000, 18 per cent of students described themselves as "very dissatisfied" with their tutorials, the third most cited reason for student dissatisfaction, following issues of time and work pressures. Six per cent stated they dropped out because they were not happy with their tutor.

\section{Reasons for Withdrawal at Various Points along the Learning Journey}

Data from a 1998-2000 survey suggest that Open University students perceived "lack of time" as the most significant factor influencing their decision to withdraw. Domestic factors, such as balancing work and family obligations, also ranked high. Other factors such as illness, death, divorce, house removal, and job loss were also cited. When combined, these factors compound and greatly muddy the issue of student withdrawal. However, there is also evidence from survey and other research work carried out as part of the Retention Programme, that the Open University may be causing, or at least contributing, to its own students' sense of overload. Many students report that the courses in which they enrolled took more time, or it was too dense in terms of the pace of programmes, than they had expected. Nonetheless, these data also reveals unrealistic expectations on behalf of students, in terms of what they can actually accomplish in the time available for course completion.

With respect to student withdrawal, there is considerable variation between courses. For instance, the numbers of students claiming increased pressures at home or work as the reason for dropping out varied between 32 per cent (Health and Social Care Course) and 69 per cent (Arts Course).

Other factors cited by students who chose to withdraw include "unhelpful" course information, and dissatisfaction with tutorials and tutors. Nonetheless, these surveys also reveal interesting insights into students' expectations and how they might be met by distance education. External costs in supporting distance education studies are frequently cited as the reason for withdrawal, such as the price of attending residential schools, computing costs, travel expenses to tutorials, and childcare costs. Clearly these are all extenuating financial factors students should ideally consider before embarking on a programme of study.

Data collected by the Open University (and generally by most other higher education institutions) are not of a type or form that can be fully relied upon to show the range of students' perceptions regarding their educational experiences that could subsequently led to their decision to withdraw. However, there are strong indications that students are under considerable pressure to juggle home, work, and study commitments, conditions that often play a factor in students' decision to withdraw. Institutions are nonetheless in a position to anticipate potential problems, simply because external pressures interact with institutional factors in such as manner that the institution can often anticipate the challenges faced by students studying in the distance mode. Put simply, higher education institutions are usually in a position anticipate and deal with problems when and where they arise. By working to positively integrate students into the institutional setting, higher education providers are in a position to positively influence student behaviour. This is essentially the basis of Tinto's (1975) model for retention, which argues that if institutions concentrate on improving their students' learning experience, they will be more likely persist in their course of studies. 
Tresman, Towards a Strategy for Improved Student Retention in Programmes

\section{A Strategy for Addressing Student Retention Issues}

The Open University has recently developed a mid-point QI strategy designed for increasing student enrolment in courses and/or programmes of study leading to awards. A number of themes that encapsulate different phases of the student-learning journey have been identified, around which strategies have been formulated to link to the Student Value Chain, a model that takes into account previous research in this area (Martinez 1997; McGivney, 1996; Peterson et al., 1997).

\section{Managing Open Entry - Where the Learning Journey Begins}

The concept of open entry brings with it potential pitfalls, the most notable being that the University's open door policy must be closely monitored so it does not become a "revolving door policy," where students are admitted only to subsequently withdraw somewhere along their learning journey.

One strategy is that higher education institutions must ensure students are not pitched into a level of study in which they cannot possibly cope. By paying close attention to admissions policies (e.g., entry restrictions to higher level courses, the use of course prerequisites, preferred entry courses at the lowest/lower course level(s), providing bridging or preparatory work prior to commencing courses of study, adequate testing and guidance from the outset), institutions can help their students achieve their educational goals in a realistic, step-by-step manner.

\section{Provisions for Specialised Advisory and Guidance Staff - Help Students Make Informed Choices}

By providing specialized advisory and guidance staff to assist students in the course selection process, students are more likely to make "informed choices" regarding their course of studies. Clearly, informed choices make for informed students who know what they can expect.

\section{Provision of Accurate and Relevant Information - When Faced With a Wide Array of Courses, Students Must Navigate a Complex Set of Possible Choices}

By ensuring that pre-course information accurately reflects the courses offered, as well as the distance mode of study practised, students are more likely to succeed in their studies, because their expectations will be more in tune with the realities of the course. The alignment of student expectations with the realities of a given course can thus be achieved by making available a coherent set of information resources (e.g., brochures, course calendars, web sites, face-to-face counselling, information sessions, etc.) that consistently describe both the demands distance education will place on students lives, as well as a preview of curriculum on offer.

Starting from when students first apply for a course, information must be collected about students' individual intentions related to their expectations. This data collection process will help to frame and address individual educational needs, as well as ascertain what a given student perceives as "success." For some students earning a formal award will be perceived as central to their success, whereas for others, any knowledge gained is perceived a "success."

Forging and Establishing Relationships - Institutions Must Proactively Focus On Establishing Relationships With New and Returning Students 
Tresman, Towards a Strategy for Improved Student Retention in Programmes

Within the framework of gathering, designing and disseminating general and in-depth information about the institution and its courses, a "student induction programme" can serve to welcome both new students and those who return after taking a break from their studies. Such a programme will help to forge lasting relationships with new students and re-establish ties with those returning.

A human face can be put on distance learning by promptly matching students with a tutor who will not only shoulder responsibility for overseeing student progress, but who will also monitor and contact students perceived as being at risk of dropping out. Other useful strategies to enhance retention include establishing peer support networks to motivate students.

\section{Course Design - Producing and Presenting Courses Well Suited to Students' Needs}

Evidence gathered from various surveys conducted as part of the Open University's Retention Programme (supplemented with data from other areas of the university and external peer reviews) present a compelling case that issues of workload, density of concepts being taught, and the pace and manageability of the various study programmes, are all major factors that may potentially lead to students withdrawing. To combat this problem, curriculum reviews paying particular attention to student workload issues, need to be conducted at regular intervals. Where feedback indicates low student performance is linked with low satisfaction levels, it is suggested that course workload be re-examined to ensure it places realistic demands on students while remaining true to learning outcomes. It is also good practice to produce and apply standardised study templates for use across all academic units. This level of standardization helps to identify study patterns and define varying levels of workload. Within this context, curriculum managers are often helpful in providing additional guidance to students on managing workloads and promoting study skills.

Another good practise is the establishment of annual retention indicators as a central part of an internal curriculum review process. By analysing retention rates alongside other evidence uncovered during the curriculum review process, changes may be discovered that are required to improve curriculum. It is important to set retention benchmarks based on linked (feedback and attainment) performance indicators, specific to different academic units.

Procedures (i.e., rescue strategies) may also be put in place that allows students to officially interrupt their studies should extenuating circumstances dictate. Students should be permitted to carry forward any credits earned up to that point, so long as they choose to recommence their work within a reasonable period of time.

Finally, student achievement should be rewarded in a consistent manner that is meaningful to the student.

\section{Student Support Services - Ownership of Students Support Services Helps Measure Success}

There must be a system of formal "process ownership" within various sectors of the university community. It is important for "process owners" to be able and willing to assist students through critical retention milestones such as the application process, course selection, studying for exams, and providing after-exam support. Each "process owner" needs to understand the fundamentals of two-way communication and the role ongoing support plays in encouraging persistence and discouraging withdrawal. Support may be provided by: 
Tresman, Towards a Strategy for Improved Student Retention in Programmes

- A course tutor, who through the execution of their tutorial responsibilities, clearly and consistently encourages persistence and discourages withdrawal.

- A specialist advisory staff member, who during the application process, strives to closely match student needs with their chosen course of study. Advisory staff must also help to students to set realistic and achievable goals.

- Students can be given ready access to their own academic records, thus being enabled to personally assess their own progress over the duration of their studies.

- Other retention strategies include establishing "hand-over" or "continuity of care" procedures, designed to ease they way for students passing on to new courses and different tutors. Support mechanisms can also be developed for vulnerable students (in terms of what we know from research as indicated by lower student retention rates) such as those with special needs, minority ethnic groups, and those studying in large urban areas.

\section{The Educational Community - Develop a Sense of Community That is Relevant in a Distance Education Setting}

By developing peer support and mentoring networks, the student experience can be greatly enhanced. Such networks can include student ambassadors, career advisors, and academic and course counsellors.

For those students who choose to leave the university for any reason, mechanisms must be established to encourage these "drop-outs" to someday return to their studies. This can be achieved by following-up with telephone calls, formal correspondence and the like.

\section{Retention Bonuses - Develop “Retention Friendly” Financing and Incentive Schemes to Encourage Student Persistence}

Good tools to consider are loyalty bonuses, vouchers, discounts that reward successful course completion, and graduation incentives to for students who are "nearly there."

\section{Reflection on this Topic}

If student persistence and withdrawal are significantly influenced by students' study and learning experiences (Tresman \& Fox, 1996), then it is reasonable to assume that higher education institutions are in a position to increase their retention rates by improving their students' experiences (Martinez, 1997). Such is the intention of The Open University, UK. By putting into operation a process whereby the student learning process is mapped from genesis to course completion, issues of "non-completion" be formally recognised as problems that need to be resolved. Thus, higher education institutions can be better equipped to compete in the so-called market economy.

To date, the causes of non-completion at the Open University have been investigated and a retention strategy has been developed. These institutional responses are currently being debated and implemented across the organisation, after which the approved strategy will be monitored and adapted according to data gathered from institutional performance indicators. 


\section{References}

Ball, S. (1995). Intellectuals or Technicians? The urgent role of theory in educational studies. British Journal of Education Studies 43(3), 255-271.

Ball, S. (1997). Policy sociology and critical social research: a personal review of recent education policy and policy research. British Educational Research Journal 23(3), 257274.

Ball, S., Maguire, M., and Macrae, S. (1997b). The Post-16 Education Market: Ethics, interests and survival. Paper presented at BERA Conference, York, UK. September 11-14.

Capper, C., and Jamison, M. (1993). Let the Buyer Beware: Total quality management and educational research and practice. Educational Researcher 22, 25-30.

Carr, W. (1997). Philosophy and method in educational research. Cambridge Journal of Education 27(2), 203-209.

Chaffee, E., and Sherr, L. (1992). Quality: Transforming postsecondary education. ASHE-ERIC Report No 3. Washington, DC: George Washington University, School of Education and Human Development.

Kember, D. (1995). Open Learning Courses for Adults: A model of student progress. Englewood Cliffs, NJ.: Education Technology Publications.

McGivney, V. (1996). Staying or leaving the course. Leicester, UK.: NIACE.

Martinez, P. (1997). Improving Student Retention: a guide to successful strategies. Further Education Development Agency, London.

Peterson, S, Kovel-Jarboe, P., and Schwartz, S. (1997). Quality Improvement in Higher Education: implications for student retention. Quality in Higher Education 3(2), 131-141.

Schwartz, S. (1990). Application of a conceptual model of college withdrawal to technical college students, a paper presented to the American Research Association Boston, April 1990.

Schwartz, S., and Peterson, S. (1993). Student Perceptions of Quality: Implications for retention in vocational education. Journal of Vocational Special Needs Education, 15, 13-18.

Tinto, V. (1975). Dropout Form Higher Education: A theoretical synthesis of recent research. Review of Education Research 45, 89 - 125.

Tresman, S., and Fox D. (1996). Meeting In-service Needs in Primary Science Using Reflective Diaries: An Occasional Paper, No. 10. Centre for Science Education, Open University UK.

Tresman, S. (2001). Learning Journeys and Student Retention in Programmes of Open Distance Education: a case study from the Open University UK, Proceedings of the 20th World 
Conference on Open Learning and Distance Education: The Future of Learning Learning for the Future: Shaping the Transition. April 1-5, 2001, Düsseldorf Germany.
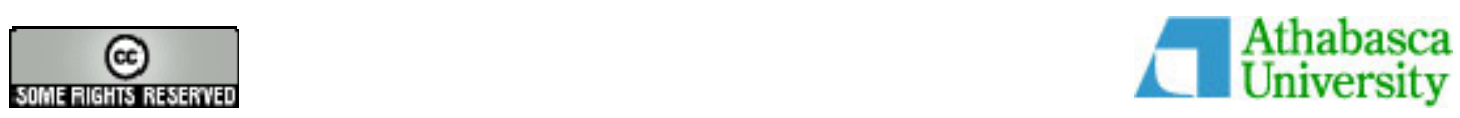